\title{
Methodology for calculation of minimum transfer time in the transport hub
}

\author{
Martin Vojtek ${ }^{1 *}$, Tomas Skrucany ${ }^{1}$, Martin Kendra ${ }^{1}$ and Jan Ponicky ${ }^{2}$ \\ ${ }^{1}$ Universtiy of Zilina, Faculty of Operation and Economics of Transport and Communications, Slovakia \\ ${ }^{2}$ Railway of Slovak republic, Slovakia
}

\begin{abstract}
The most important element in railway passenger transport is a customer - traveller, who requires the transport from one place to another. A basic precondition for accomplishing the main requirement transport, is making the complete offer which provides not only transport, but also other associated services. Practically, there are many associated criteria of transport, for example safety, duration, price, reliability, comfort and complementary services. Passenger transport is generally considered as an activity, which arises as the consequence of spatial division of places, where people are in exact time and their need to move. Motivators for moving could be commuting - job or education, dealing with personal or working matters, travelling for vacation - hiking, sport, health, cultural and social facilities, visiting relatives and friends. Requirements for transport of passengers originate in the need to move, while the passenger transport is dependent on the willingness of travelling. In passenger transport, there are mostly individual passengers, so it is difficult to determine all transport requirements. The paper is focused on one of the key factors of passenger transportation - connectivity of trains. Connectivity of passenger trains and other means of transport can be distinguished also from temporal and spatial point of view. Temporal connectivity is such sequence of arrivals and departures of different passenger trains and other means of transport, which allows changing the different passenger vehicles easily in regard to necessary time. Spatial connectivity means the distance between two passenger vehicles, among which the passenger is moving. In the paper, there is described the general methodology for calculation of minimum transfer time in the railway station. Railway passenger station is some kind of transport hub - a starting and finishing point for flows of passengers. Passengers have the opportunity to change the train type from long-haul train to regional train or contrariwise or simply enter or leave the system of railway transport. In the methodology, all necessary aspects are taken into account.
\end{abstract}

\section{Introduction}

Transport network consists of transport routes and transport hubs $[1,2]$. The transport hub is important part of passenger transport process. In the transport hub, a vehicle could be changed in the same or different type of transport [3]. It is necessary to ensure suitable constructional layout, which would provide safe, fast and comfortable transfer of passengers among vehicles of the same or different type of transport [4, 5]. Additional services for passengers are also one of the significant factors $[6,7]$ because passengers could use them while they are waiting. In the transport process, it is very important to minimize waiting time from temporal point of view, but all conditions for safe transfer and sufficient time for it must be kept $[8,9]$. The paper is focused on a methodology, which can exactly stipulate the minimum transfer time in the transport hub among various vehicles and types of passenger transport. Currently, transfer times are set empirically or by estimation. When some lack is identified, transfer times are operationally adapted to passengers' requirements [10]. General methodology for solving transfer problems in transport hubs is described in the paper.

\section{Characteristics of passenger transport chain}

In the passenger transport system, the element is an object, which cannot be divided into smaller parts during transport process. Transport requirements represent the relocation of passengers therefore the object of transport is the passenger. All passenger transport systems could be characterized by [11]:

- Places of getting on, getting off and getting among vehicles,

- Transport hubs,

- Sections between pairs of transport hubs, which are performed always with one vehicle,

- Mutual aim of fast, safe, comfortable and reliable transportation.

Appropriate methodology of temporal elements quantification could detect some bottle necks of transportation process, which must be subsequently modified for purpose of improving quality and efficiency of public passenger transport.

* Corresponding author: martin.vojtek@fpedas.uniza.sk 


\section{The methodology for setting the minimum transfer time in transport hub}

The proposed methodology is based on exactly established approaches, which must be abided for reaching the aim - determination of necessary minimum transfer time in transport hub for various groups of passengers.

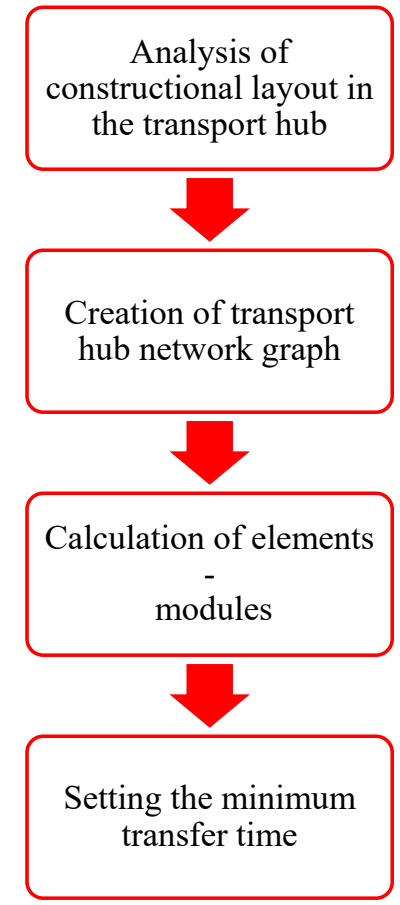

Fig. 1. Process of proposed methodology

\subsection{Analysis of constructional layout in the transport hub}

Constructional layout in the transport hub significantly influences the minimum transfer time, which are necessary for passengers in case of changing the vehicle or mode of transport in the transport hub [12].

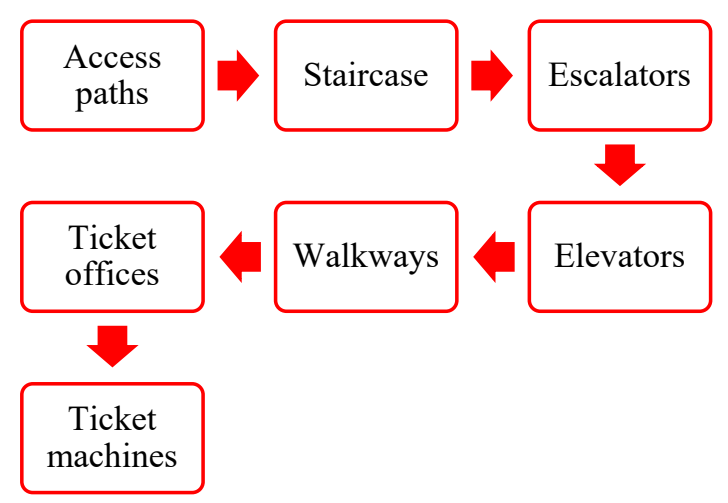

Fig. 2. Constructional layout parts which influence the transfer time

Access paths should connect all public spaces in the transport hub with way, which must be as short as possible. They should be signed by visual tools for better orientation and their surface should be anti-skid. In the analysis, it is necessary to identify all access paths, which could be used by passengers. Also it is necessary to identify access paths for PRM passengers. Identification of access paths length is necessary for calculation of elements (modules) in the transport hub. Another part, what impacts the transfer time, is a staircase. $[13,14]$ In the analysis, it is important to determine their location in the transport hub (different passenger frequency) and number of stairs. The elevator is a transport device for vertical transport of passengers. In the analysis, it is necessary to determine the location of elevators in the transport hub, because the frequency of passengers could be different. Then, it is important to determine the time of opening doors, transport velocity of elevator and floor size, because these indicators directly influence the transport capacity of passengers. Escalators and walkways are devices for horizontal and vertical transport of passengers in the building. Their advantage is higher transport capacity than elevators. It is necessary to analyse their location in the transport hub, transport velocity and constructional length. Ticket offices and machines situated in the transport hub ensure travel tickets selling for passengers. In the analysis, it is important to determine the number of them (number of desks, machines etc.) and their opening hours.

\subsection{Creation of transport hub network graph}

The network graph presents a unique way of mathematical expression for temporal or technological sequence of partial operations. In the proposed methodology, the network graph of transport hub is evaluated by vertices and edges. Edges of network graph represent oriented lines between vertices. Edges in the graph show access paths in the transport hub. The evaluation of edges is time $\mathrm{t}$ which is necessary for getting across the access paths by passengers. Vertices of network graph represent activities, which must be accomplished by passenger during transfer in the transport hub. [15] For instance: getting off the vehicle, buying travel tickets, etc. Vertices in the graph are carriers of information called modules.

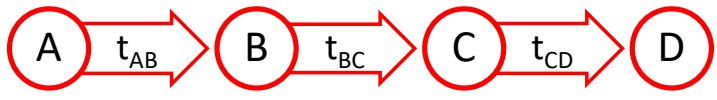

Fig. 3. Sample of network graph in the transport hub In the figure 3, A means getting off the vehicle, B means going on stairs, $\mathrm{C}$ means buying travel tickets and $\mathrm{D}$ means getting on the vehicle.

\subsection{Calculation of elements (modules) - evaluation of vertices in the network graph}

Vertices in the network graph are carriers of information about duration of each activity while transferring in the transport hub - modules. Partial indicators are:

- Getting off the vehicle time,

- Going on stairs time,

- Transport on escalators time,

- Transport in elevators time,

- Transport on walkways time, 
- Buying travel ticket time.

\subsubsection{Getting off the vehicle time}

Getting off the vehicle time is first phase, which is calculated in transfer time. This time starts after the vehicle stopped in the transport hub on the place for getting off the vehicle. Factors with significant impact to getting off the vehicle time are:

- Opening door of the vehicle time tod - set on measurement according to constructional layout of the vehicle and way of door opening mechanism,

- Vehicle door constructional layout coefficient $C_{v d c}$ vehicle door constructional layout (constructional width) has got significant impact to number of passengers and duration of boarding,

- Vehicle door load $\boldsymbol{L}_{v d}$ - vehicle door load shows proportion on number of getting off passengers and number of vehicle doors. If there are many doors on the vehicle, less time for getting on and off the vehicle is necessary,

- Platform length coefficient $\boldsymbol{C}_{\boldsymbol{p}}$ - this coefficient is set on constructional layout of the platform in the transport hub. Constructional layout of the platform could be in one grade when platform is in the same height as the floor in the vehicle, or it could be gradeseparated when the platform is not in the same height as the floor in the vehicle.

- Luggage handling coefficient $\boldsymbol{C}_{\boldsymbol{l h}}$ - it is dependent on size, weight and capacity of the luggage.

- Resultant formula for calculation of getting off the vehicle time is:

$$
\begin{aligned}
T_{o f f v}=t_{o d}+\sum_{i=1}^{n} P_{o f f p} & \\
& * \sum_{i=1}^{L_{v d}} T_{o f f p}^{i} * C_{v d c} * C_{p l} * C_{l h}
\end{aligned}
$$

where:

$\mathrm{T}_{\text {offv }}$ getting off the vehicle time [s],

tod opening door of the vehicle time [s],

Poffp number of getting off passengers [passengers],

$\mathrm{T}^{\mathrm{i}}$ offp unit time of getting off passengers according to type of passenger [s],

$\mathrm{L}_{\mathrm{vd}}$ vehicle door load [-],

$\mathrm{C}_{\mathrm{vdc}}$ vehicle door constructional layout coefficient [-],

$\mathrm{C}_{\mathrm{pl}}$ platform length coefficient [-],

$\mathrm{Clh}_{\mathrm{lh}}$ luggage handling coefficient [-].

\subsubsection{Going on stairs time}

It is necessary to divide going on stairs time into:

- Going upstairs,

- Going downstairs.

The reason of passengers' going on stairs time division into going upstairs and going downstairs is that velocity of going upstairs is lower than velocity of going downstairs. For verification of this hypothesis, the measurement in the transport hub Zilina was done. Passengers were divided into three groups:

- Group 1 - students,

- Group 2 - productive ages,

- Group 3 - pensioners.
The reason of this division is that passengers in each group are going very similar time. Entire number of measurements, which were done in each group, is 100 measurements. Number of stairs was set to 23 stairs.

The formula for calculation of going on stairs time is:

where:

$$
T_{s t}=\frac{N_{s t}}{\emptyset v_{s w}^{i}} * C_{l h}
$$

$\mathrm{T}_{\mathrm{st}}$ going on stairs time [s],

$\mathrm{N}_{\mathrm{st}}$ number of stairs [stairs],

$\varnothing \mathrm{v}_{\mathrm{sw}}^{\mathrm{i}}$ average speed of walking [stair. $\mathrm{s}^{-1}$ ],

$\mathrm{C}_{\mathrm{lh}}$ luggage handling coefficient [-].

\subsubsection{Transport on escalators time}

Entire transport time depends on individual constructional layout of the escalator in the transport hub. It means that there are these dependent parameters: transport velocity and constructional length of the escalator. For calculation of entire transport on escalators time is necessary to count all passengers, who are going on the escalator in the same time.

The calculation of transport on escalators time should be:

1. passenger: $t_{1}$

2. passenger: $t_{1}+t_{i}$

3. passenger: $t_{1}+2 * t_{i}$

n. passenger: $t_{1}+(n-1) * t_{i}$

Transport on escalators time of the first passenger is set by formula:

$$
t_{1}=\frac{L}{v_{e}}
$$

where:

$t_{1}$ transport on escalator time of the first passenger [s],

$\mathrm{L}$ constructional length of the escalator [m],

$\mathrm{V}_{\mathrm{e}}$ escalator velocity $\left[\mathrm{m} \cdot \mathrm{s}^{-1}\right]$.

For every other passenger, it is necessary to count with transport on escalator time of the first passenger and increased time on escalator which depends on other passenger order from the first passenger on escalator. Increased time of another passenger on escalator is set by formula:

where:

$$
t_{i}=\frac{l_{p}}{v_{e}}
$$

lp distance between the passengers on the escalator [m].

If there is possible to stand of more passengers next to each other on the escalator, order of the passengers (1. passenger, 2. passender, 3. passenger,..., n. passenger) means order of the m-tuble of the passengers on the escalator, where $\mathrm{m}$ is number of passengers who can stay next to each other on the escalator.

\subsubsection{Transport in elevators time}

The entire transport in elevators time depends on individual constructional layout of the transport hub. Getting off the elevator time starts after the elevator stops on the floor. It is set by formula: 


$$
T_{o f f}^{e}=t_{o e d}+\frac{\sum_{i=1}^{n} T_{o f f_{i}}^{e} * N_{p}}{C_{e d}}
$$

where:

$t_{\text {oed }}$ opening doors of elevator time [s],

$\mathrm{T}_{\text {offi }}$ getting off the elevator time per passenger [s],

$\mathrm{N}_{\mathrm{p}}$ number of getting off passengers [passengers],

$\mathrm{C}_{\mathrm{ed}}$ constructional layout of elevator doors [-].

Getting on the elevator time starts after all getting off the elevator passengers are out of the elevator. It is set by formula:

$$
T_{o n}^{e}=\frac{\sum_{i=1}^{n} T_{o n_{i}}^{e} * N_{p}}{C_{e d}}+t_{c e d}
$$

where:

$\mathrm{T}_{\text {oni }}$ getting off the elevator time per passenger $[\mathrm{s}]$,

$t_{c e d}$ closing doors of elevator time [s].

Entire transport in elevator time is set by formula:

$$
T_{e}=T_{o f f}^{e}+T_{o n}^{e}+T_{i n}^{e}
$$

where:

$\mathrm{T}_{\mathrm{e}} \quad$ entire transport in elevator time $[\mathrm{s}]$,

$\mathrm{T}^{\mathrm{e}}{ }_{\text {in }}$ transport in elevator time [s].

\subsubsection{Walkways module}

Walkways are suitable for mass transport of people in shopping centres and transport hubs. In general, transport on walkways time is set by the same formula as for transport on escalator.

\subsubsection{Buying travel ticket time}

A place, where passengers can buy ticket is a typical example of Queueing theory systems. Basic model is system $\mathrm{M} / \mathrm{M} / \mathrm{n} / \infty$ with $\mathrm{n}$ possibilities for buying the travel ticket. Arrivals of passengers are described with Poisson's distribution with $\lambda$ frequency and duration of service has got exponential distribution with average duration $1 / \mu$. All buying possibilities are equally productive. Passengers are served in the same order as they came to the system. The entire time in the system - average duration in the system is a sum of average time of waiting in the queue and time of buying the travel ticket. It is set by formula:

$$
E(R)=\frac{\pi}{n * \mu-\lambda}+\frac{1}{\mu}=\frac{\frac{\rho^{n}}{n !} * \frac{1}{1-\frac{\lambda}{n * \mu}} * p_{0}}{n * \mu-\lambda}+\frac{1}{\mu}
$$

\subsection{Calculation of elements (modules) - valuation of edges in the network graph}

Edges in the network graph represent oriented lines between vertices (passengers' activities in transport hub during the transfer). Vertices are access paths in the transport hub.

\subsection{Walking on access paths time}

Access paths would connect all public spaces in the transport hub by way which is as short as possible. Another module for valuation of transport connectivity in public transport system is setting necessary time for reach these distances. In this measurement, passengers were divided into three groups again, similarly as it was in the measurement of going on stairs time. Entire number of measurements was 100 and the distance was 45,5 meters. According results of these measurements, average time and velocity of walking was set for each group of passengers. The formula for calculation of walking on access paths:

$$
T_{\text {wap }}=\frac{L}{\emptyset v_{w a p}^{i}} * C_{l h}
$$

where:

$\mathrm{T}_{\text {wap }} \quad$ walking on access paths time [s],

L distance [m],

$\varnothing v_{\text {wap }}^{\mathrm{i}}$ average velocity of walking according to group of passengers $\left[\mathrm{m} \cdot \mathrm{s}^{-1}\right]$,

$\mathrm{C}_{\mathrm{lh}} \quad$ luggage handling coefficient [-].

In case, when the passenger is getting of the vehicle, it is important to calculate with the distance of the furthest doors of the vehicle.

\subsection{Setting the minimum transfer time}

The result of the network graph application in the transport hub and by counting the modules is setting the minimum transfer time in all combinations of edges and vertices, which could be possible while passengers are transferring in the transport hub.

\section{Conclusions}

1. Proposal of the network graph in the transport hub with valuation of edges and vertices

2. Calculation of transferring passenger partial activities

3. Possibility of constructional layout integration in the transport hub

4. Possibility of constructional layout integration in vehicles

5. Simplification of timetables in integrated transport systems

6. Optimization of transfer times according to passengers' needs

This research was financially supported by the project VEGA No. 1/0019/17 Evaluation of regional rail transport in the context of the region's economic potential focusing on the efficient use of public resources and social costs of transport.

\section{References}

1. B. Abramović, PPTE, 45, 42-47 (2017)

2. J. Camaj, J. Masek, A. Dolinayova, J. Danis, ICTTE 2016, 955-963 (2016) 
3. R. Kampf, S. Lorincova, M. Hitka, O. Stopka. Sustainability, 9. (2017) DOI: 10.3390/su9091561

4. J. Gašparík, V. Luptak, P. Meško, ICTTE 2016, 388392 (2016)

5. R. Berezný, V. Konecný, Procedia Engineering, 192, 40-45 (2017)

6. J. Gasparik, V. Luptak, P. Mesko, P. V. Kurenkov. Communications, 19, 2, 61-67 (2016)

7. V. Zitricky, J. Gasparik, L. Peceny. Transport problems. 10, SI. 59-72. (2015)

8. J. Gnap, V. Konecny, Kom., 10, 55-59 (2008)

9. E. Brumercíkova, B. Bukova, P. Kondek, LOGI 2017 (MATEC Web of Conferences), 134, 00002 (2017)
10. C. Csiszar, D. Foldes, CogInfoCom 2015 Proceedings, 7390578 (2016)

11. L. Bartuska, V. Biba, R. Kampf. Proceedings of the Third International Conference on Traffic and Transport Engineering. (2016) WOS:000391016300128

12. L. Hansut, A. David, J. Gasparik. Bussines Logistic In Modern Management. 29-42. (2017)

13. D. Foldes, C. Csiszar, SCSP 2016, 7501022 (2016)

14. S. Stoilova, TV-TG, 25, 587-595 (2018)

15. M. Gogola, Transport Means - Proceedings of the International Conference, 2015, 359-362 (2015) 